\title{
Public Orchestration, Social Networks, and Transnational Environmental Governance Lessons from the Aviation Industry
}

Henriksen, Lasse Folke; Ponte, Stefano

Document Version

Accepted author manuscript

Published in:

Regulation and Governance

DOI:

10.1111/rego.12151

Publication date:

2018

License

Unspecified

Citation for published version (APA):

Henriksen, L. F., \& Ponte, S. (2018). Public Orchestration, Social Networks, and Transnational Environmental Governance: Lessons from the Aviation Industry. Regulation and Governance, 12(1), 23-45.

https://doi.org/10.1111/rego.12151

Link to publication in CBS Research Portal

\section{General rights}

Copyright and moral rights for the publications made accessible in the public portal are retained by the authors and/or other copyright owners and it is a condition of accessing publications that users recognise and abide by the legal requirements associated with these rights.

\section{Take down policy}

If you believe that this document breaches copyright please contact us (research.lib@cbs.dk) providing details, and we will remove access to the work immediately and investigate your claim. 


\section{Public Orchestration, Social Networks, and Transnational Environmental Governance: Lessons from the Aviation Industry}

\section{Lasse Folke Henriksen and Stefano Ponte}

Journal article (Accepted manuscript)

This is the peer reviewed version of the following article: Henriksen, L. F., \& Ponte, S. (2018). Public Orchestration, Social Networks, and Transnational Environmental Governance: Lessons from the Aviation Industry. Regulation and Governance, 1211, 23-45. D01: 10.1111/rego.12151, which has been published in final form at http://dx.doi.org/10.1111/rego.12151.

This article may be used for non-commercial purposes in accordance with Wiley Terms and Conditions for SelfArchiving.

Uploaded to Research@CBS: January २०19 


\title{
Public orchestration, social networks, and transnational environmental governance: Lessons from the aviation industry
}

Lasse Folke Henriksen ${ }^{1}$ and Stefano Ponte ${ }^{2}$

\begin{abstract}
This article contributes to current debates on the potential and limitations of transnational environmental governance, addressing in particular the issue of how private and public regulation compete and/or reinforce each other - and with what results. One of the most influential approaches to emerge in recent years has been that of "orchestration." But while recent discussions have focused on a narrow interpretation of orchestration as intermediation, we argue that there is analytical traction in studying orchestration as a combination of directive and facilitative tools. We also argue that a social network analytical perspective on orchestration can improve our understanding of how governments and international organizations can shape transnational environmental governance. Through a case study of aviation, we provide two contributions to these debates: first, we propose four analytical factors that facilitate the possible emergence of orchestration (issue visibility, interest alignment, issue scope, and regulatory fragmentation and uncertainty); and second, we argue that orchestrators are more likely to succeed when they employ two strategies: (i) they use a combination of directive and facilitative instruments, including the provision of feasible incentives for industry actors to change their behavior, backed up by regulation or a credible regulatory threat; and (ii) they are robustly embedded in, and involved in the formation of, the relevant transnational networks of actors and institutions that provide the infrastructure of governance.
\end{abstract}

\section{Introduction}

The challenges involved in tackling global environmental problems, such as increasing greenhousegas emissions, are enormous. Regulation by nation states is only effective globally if all major polluting countries apply similar measures. International agreements that can provide common regulatory platforms have been difficult and slow to negotiate. Even when successfully concluded, key polluting industries may remain out of their remit - international shipping and aviation, for

\footnotetext{
1 Copenhagen Business School, Department of Organization, lfh.ioa@cbs.dk

${ }^{2}$ Copenhagen Business School, Department of Management, Society and Communication, spo.msc@cbs.dk
} 
example, are not covered by the Paris Agreement, thus limiting its effectiveness. In parallel to these processes, a wide range of voluntary, experimental and innovative governance initiatives have emerged at various geographic scales to tackle environmental challenges, from networks of cities to multi-stakeholder initiatives on sustainability - often driven by, or operated in cooperation with, business, industry associations and civil society groups. The existing fragmentation of governance fields limits the aggregate effects of these initiatives, due to possible duplication or conflict between them. How can governments and international organizations avoid hampering innovation and variety, at the same time as ensuring that these initiatives pull in the same direction? In this article, we provide a contribution to answering this question through a theoretical engagement with the nascent field of 'public orchestration' and the empirical case study of the aviation industry.

Aviation is one of the main global GHG-emitting industries, and one where change is hampered by low operating margins and made slow by the dominance of capital intensive and mobile assets (Gossling and Upham 2009). Its main international regulatory body, the International Commercial Aviation Organization (ICAO) has been ineffective at providing global regulation on the environmental impacts of the industry. At the same time, a variety of voluntary initiatives have emerged, but with important orchestration functions carried out by the US and the EU, including key roles played in the construction of a globally-connected network on aviation biofuels. This case study provides an opportunity to learn important lessons on how national and (in the case of the EU) regional governments can exercise orchestration in absence of an effective global regulator - a condition that is common in many industries and regulatory fields.

Our contribution speaks directly to current debates on the potential and limitations of transnational environmental governance, but is framed within a broader debate (to which Regulation \& Governance has provided key contributions) on the interactions between private and public regulation as separate fields that can either compete or reinforce each other. The existing literature suggests that private regulation started strengthening from the 1980s onwards as a result of failure by (or retreat from) public authority in regulating pressing social and environmental challenges especially those with a transnational or global character - eventually leading to a crowding out of public regulatory instruments by private regulation (Cutler et al. 1999; Bartley 2007; Vogel 2008). An alternative argument has been that public authorities remain key not only in providing legitimacy to private regulation, but also in facilitating its compliance (Black 2003; Gale and Haward 2011; Foley 2013; Verbruggen 2013; Gulbrandsen 2014; Mills 2016). A main preoccupation in this literature has thus been the interplay of government, civil society and business (Avant et al. 2010) to understand how they compete and/or cooperate to shape rule systems and 
achieve legitimacy (Bernstein and Cashore, 2007; Black, 2008; Fransen, 2012; Eberlein et al. 2014), with particular attention paid to the effects of alignment and misalignment of interests between industry and the state (Verbruggen 2013; Gulbrandsen 2014; Auld 2014; Mills 2016).

This vast body of literature has provided important insights in unpacking the complexity of transnational governance fields variously conceptualised as 'hybrid governance' (Ponte and Daugbjerg 2015), ‘ensemble regulation' (Perez 2011), 'partnered governacne’ (Hale and Roger 2014) 'regulatory ecosystems' (Meidinger 2009), 'co-regulation' (Sinclair 1997; Gunningham and Sinclair 2002; Gunningham 2009) and 'responsive regulation' (Ayres \& Braithwaite 1992; Abbott and Snidal 2013). There has also been a growing interest in understanding how interests can be (and have been) made to align - in other words, whether and how public authority can (or should) work to bridge possible gaps between different groups of public, private and civil society actors and/or work to shape established positions to new realities. This literature examines how public authorities can 'steer' an existing variety of private and hybrid governance instruments to promote desired outcomes. Examples are Braithwaite and Drahos (2000) and Black (2003), who have variously employed the concept of 'enrolment' for this purpose; Hale \& Roger (2014), who have used the concept of 'steering'; and Overdevest \& Zeitlin (2014), who have applied the lenses of experimental governance to examine processes such as benchmarking. One of the most influential approaches emerging in recent years, however, has been that of 'orchestration': while not diverging substantially from the concerns of experimentalist governance and from the concept of 'steering', orchestration has provided an intuitive heuristic device that reflects the current complexities of governing: as the conductor of an orchestra needs to make all her musicians work together, so needs public authority to align different kinds of instruments - some of which it has some degree of control and influence upon, and some of which it can only indirectly shape or facilitate (Abbott and Snidal 2009a; 2009b; 2010; 2013; Schleifer 2013; Hale and Roger 2014; Abbott et al. 2015).

In our article, we use a slightly different term, 'public orchestration' to even more explicitly signal a concern with tools and combination of instruments that public regulatory bodies can use to shape transnational environmental governance. These can involve indirect tools and soft power in view of steering industries and citizens towards addressing global problems, but also more direct regulatory tools, regulatory threats and/or incentives - thus including instruments that nudge actors towards self-regulation and those seeking public and private sector co-regulation (as in Gunningham and Sinclair 2002; Albareda 2008; Héritier and Eckert 2008; Gunningham 2009). Although the more recent literature has focused on international organizations as possible orchestrators (Abbott et al. 2015), our main proposition is that in regulatory fields or industries lacking an effective 
international organization that handles environmental concerns, key national/regional governments can play key roles as orchestrators of transnational environmental governance.

In this article, we engage in theory building and descriptive inference to provide two sets of arguments. First, we propose four analytical factors that facilitate the possible emergence of orchestration: issue visibility; interest alignment; issue scope; and regulatory fragmentation and uncertainty. Second, we argue that orchestrators are more likely to succeed when they employ two strategies: (1) the use a combination of directive and facilitative instruments, including the provision of feasible incentives for industry actors to change their behavior backed up by regulation or a credible regulatory threat; and (2) are 'robustly' embedded in, and involved in the formation of, the relevant transnational networks of actors and institutions that provide the infrastructure of governance.

In our study, we specifically stress the importance for public orchestrators of embedding themselves within networks of experts and other stakeholders, an aspect that has been rarely explored in the literature so far (for recent exceptions, see Author Reference a; Author Reference b; Fransen 2015; Fransen et al. 2016). These networks can be used to stay informed on what industry is doing and to communicate signals to industry about where policies are headed. The use of social networks to orchestrate the interplay of various governance instruments is an important yet understudied aspect of orchestration - especially in the context of transnational governance processes. Through our analysis of public organizations' position within the issue-specific social network of aviation biofuel - alongside in-depth qualitative analysis of the institutional features and trajectories of governance initiatives - we are able to assess the relative prominence of different public organizations and provide insights about how this might reflect on their ability to orchestrate. Our combination of interpretive analysis and Social Network Analysis (SNA) helps us provide insights on orchestration that are at the center of current theoretical debates, but that need further empirical exploration - including what role (national and regional) public organizations play in transnational governance interactions (Eberlein et al. 2014). Using a novel network data set on aviation biofuels developed by the authors, Exponential Random Graph Models (ERGM) are applied to model the relational configuration of public orchestrators, including what mix of actors they interact with in learning and information-sharing networks. 


\section{Transnational Environmental Governance and Orchestration}

What we call transnational environmental governance (TEG) in the rest of this article consists of 'transnational actors operating in a political sphere in which public and private actors interact across borders and political jurisdictions' (Andonova et al 2009, 69) to address environmental concerns. TEG is fragmented, multi-layered, characterized by a hybrid of private and public authority and takes place through different kinds of partnerships - frequently involving the steering of networks to achieve public policy goals (Haas 2004; Bäckstrand 2008; Andonova et al. 2009; Andonova 2010). Yet, we still know too little about the characteristics of these networks, who steers them, and to what degree they are steered.

A major area of interest in the TEG literature has been establishing the extent to which private authority has led to a wholesale retreat of the state or to new overlaps between public and private spheres (Cashore et al. 2004; Bartley 2007; Bernstein and Cashore 2007; Pattberg 2007; Guldbrandsen 2010; Büthe and Mattli 2011). A now extensive literature has usefully shown that state capacity still has a crucial role in facilitating the emergence, implementation, and enforcement of private regulation, and that successful public support is more likely to happen when norms, objectives, and interests overlap between the public and private spheres (Gale and Haward 2011; Foley 2013; Verbruggen 2013; Auld 2014; Bartley 2014; Guldbrandsen 2014). Other work has focused on understanding the numerous transnational experiments and entrepreneurial governance initiatives that are being carried out by cities and their networks, industry associations and individual corporations, international and local NGOs, and other non-state actors (Dingwerth and Pattberg 2009; Andonova et al. 2009; Overdevest 2010; Hoffmann 2011; Bulkeley et al. 2012; Green 2013; 2014; Overdevest and Zeitlin 2014).

For the purpose of this article, we engage specifically in TEG debates that are concerned with the possible mechanisms and strategies that nation states and international organizations can use to shape environmental outcomes (Keohane and Victor 2011; Hale and Rogers 2014; Abbott et al. 2015; Graham and Thompson 2015). A major source of concern in this realm remains the 'fragmentation' of governance architectures in the environmental field and the resultant 'governance deficit' (Haas 2004; Biermann et al. 2009; Zelli and van Asselt 2013). Although new experimentation and innovation in TEG was ushered by the 1992 Earth summit in Rio, nation states and international organizations are only slowly coming to terms with the complexity of emerging multi-level and decentralized governance initiatives, and are starting to act as 'entrepreneurs to 
facilitate collaboration with non-state actors within their spheres of expertise' (Andonova 2010, 26; see also Andonova and Hoffman 2012).

The concept of orchestration provides an explicit analytical and normative tool in addressing the current TEG deficit. Orchestration entails paying critical attention 'not only to who is involved in transnational governance, but also to the ways in which transnational networks deploy different sources of authority and mechanisms of steering in order to govern' (Andonova et al 2009, 57). It goes beyond the established distinctions between self-regulation, co-regulation and hierarchy (Sinclair 1997) to highlight the combinations that may be successful to push forward an environmental agenda in transnational governance.

Abbott and Snidal (2009b) distinguish two broad sets of mechanisms under the concept of 'orchestration', some of which are defined 'directive' and others 'facilitative' (see also Schleifer 2013). On the one hand, they see directive orchestration as relying on the authority of the state and seeking to incorporate private initiatives into its regulatory framework (through mandating principles, transparency, codes of conduct). On the other hand, they conceive facilitative orchestration as relying on softer instruments, such as the provision of material and ideational support (financial support, technical support, endorsement) in order to kick-start new initiatives and/or to further shape and support them. Similarly, Hale and Roger see orchestration as 'a process whereby states or inter-governmental organizations initiate, guide, broaden, and strengthen transnational governance by non-state and/or sub-state actors' (Hale and Roger 2014, 60-61), and distinguish between 'initiating' orchestration, where states or IOs are active in forging a new initiative, and 'shaping' orchestration, where they lend support to already existing initiatives.

More recently, Abbott et al. (2015; see also Graham and Thompson 2015) have taken a narrower view of orchestration as happening when an international organization 'enlists and supports intermediary actors to address target actors in pursuit of ... governance goals'. Orchestration, from their current perspective, is a specific form of governance characterized by soft instruments and indirect influence on target actors, in what they call the 'O-I-T model' (orchestrator-intermediarytarget). In this interpretation, intermediation and orchestration are used synonymously to identify a specific form of governance that is distinguished from other three forms: (1) hierarchy, the more traditional form where a governor applies hard regulatory tools directly to its targets; (2) delegation, where the governor uses hard regulatory tools but delegates the regulatory function to another party, thus has indirect influence (Green 2013; 2014); and (3) collaboration, where the governor 
utilizes soft tools, such as ideational or material incentives, and collaborates directly with the targets of regulation (Cutler 1999).

In Abbott et al.'s (2015) model, intermediation is indirect, because orchestrators enlist an intermediary institution between them and the targets of regulation, and is soft because it uses facilitative instruments. They also propose a series of hypotheses to explore when intermediation is more likely to work. These are: (1) low orchestrator capabilities in focal domain; (2) intermediary availability; (3) low orchestrator focality (other actors are also operating in the governance domain); and (4) an organizational structure that facilitates entrepreneurship. To these, they add two hypotheses that apply specifically to international organizations: (5) there is divergence of goals among member states; and (6) there is weak oversight of member states in the focal domain (Abbott et al. 2015: 20-30). These conditions, with the exception of 'organizational culture', are based on rational choice and institutionalist considerations. As we will discuss below, some of these factors explain why the relevant international organization (ICAO) did not use intermediation in transnational environmental governance of aviation. However, they do not explain why and how other public authorities (in the US and the EU), in absence of ICAO's action, were actually successful in orchestrating transnational (not only domestic) environmental governance.

In our article, we take three points of departure from Abbott et al.'s (2015) approach: (1) we refocus on the role that national and regional regulators can play in orchestrating transnational environmental governance, a key feature especially in regulatory fields or industries lacking an effective international organization; (2) we return to the broader conceptualization of orchestration as a tool used by public orchestrators to steer TEG through a combination of different instruments direct and indirect, soft and hard; and (3) we identify key factors of orchestration through a mixture of institutionalist, evolutionary and sociological approaches, including the examination of how these instruments can be woven together through network formation and maintenance.

We do so in recognition that public governors often use a combination of mechanisms, including network formation, in attempting to achieve policy goals, and that outcome effectiveness is linked to different combinations of these mechanisms in the context of industry or issue specificity, rather than the superiority of one governance form over another. In our approach, intermediation is indeed an important governance tool to be examined, but does not equate with orchestration. In other words, orchestrators may combine hard regulatory tools with softer instruments such as mandates or subsidies, sometimes combined with the threat of future/stronger regulation, an aspect not captured by either 'hard' or 'soft' instrument classification. Orchestrators, when using soft instruments, may 
also operate both directly and through intermediaries. Furthermore, they can combine hierarchy, collaboration, delegation and intermediation with other hybrid mechanisms, such as placing their representatives in regulatory intermediaries - an approach that is neither pure intermediation (the governor populates the 'intermediary') nor collaboration (the governor does not regulate directly). Governors can also employ different tools at different times in their historical trajectories, thus calling for an evolutionary perspective to orchestration.

Clearly, Abbott et al.'s (2015) classification is a useful heuristic device that can help disentangle the complexity of transnational governance, and that clarifies the role of intermediation - a governance instrument that has attracted less attention form researchers so far. However, we argue that what distinguishes 'orchestration' in the broader sense of the term we employ here is a focus on what combinations of regulatory tools governments and international organizations can and do use.

In our framework, we take two steps. First, we go back to the descriptive classification of orchestration instruments originally developed in Abbott and Snidal's earlier work (Abbott and Snidal 2009b) which distinguishes: (1) directive orchestration instruments, which for us include international and national regulation, 'threat of regulation', also known in the literature as the 'gorilla in the closet' or 'shadow of hierarchy' factor (Bäckstrand, 2008; Verbruggen, 2013), the incorporation of private standards, codes of conduct or transparency measures in public regulation, the provision of direct subsidies and the setting of mandates, and public procurement and other direct forms of direct financial support and investment; and (2) facilitative orchestration instruments, where public authorities either facilitate, indirectly influence, network and/or participate with other stakeholders in key initiatives or groups - such as industry associations, multi-stakeholder initiatives and industry conferences.

We thus propose that successful orchestration trajectories entail the use of plural governance tools, and a combination of direct and indirect instruments - together with active participation of the orchestrators themselves in the relevant regulatory networks. The latter aspect has remained underexplored in the literature, and we know little about what the social networks of public orchestrators look like and what types of actors they interact with learning and information-sharing networks. Given that not only facilitative, but also directive orchestration tools hinge on effective social coordination with regulatory targets (as well as with intermediaries), building relations of learning, information-sharing and trust within the broader regulatory environment is an important factor to be examined. Coordination of different instruments within specific jurisdictions in itself can be enabled through social networks, but when this is to take place across jurisdictions, acting 
through social networks can become even more important for national and regional public authorities.

Second, we propose analytical factors that can help explain (and potentially predict) the conditions that facilitate orchestration (rather than intermediation per se): issue visibility; interest alignment; issue scope; regulatory fragmentation and uncertainty. The four factors were co-developed by one of the authors elsewhere (Reference withdrawn) by drawing from some of the key insight of the literature on TEG. On issue visibility, we can expect more potential for orchestration if the industry involved, and the related set of environmental issues, are clearly visible to the general public and especially to consumers (Dauvergne and Lister, 2012). On interest alignment, we can expect better orchestration possibilities if there is substantial overlap between public and private interests, and relative cohesion internally within each sphere (Verbruggen, 2013; Schleifer, 2013). On issue scope, we can expect orchestration to be more likely to succeed when addressing a narrower and more specialized set of issues, rather than a more comprehensive set (Auld, 2014). On regulatory fragmentation and uncertainty, we can expect more difficult conditions for orchestration in situations when public regulation of environmental concerns is fragmented and uncertain, and when relevant private or hybrid initiatives are multiple and diverse (Haas, 2004; Biermann et al., 2009; Zelli and van Asselt, 2013; Alter and Meunier, 2009; Fransen, 2012).

\section{Case selection and methodology}

To test these propositions empirically, we selected the aviation sector as a case study of orchestration. The aviation industry provides a critical case study for two reasons. First, within the transport sector, it has the highest $\mathrm{CO}_{2}$ emissions per unit transported, and is projected to have a faster growth rate than other modes of transport. ${ }^{1}$ It has experienced constant growth over the last three decades, and continues to do so, spurred by low-cost airlines and growth in emerging markets (Gossling and Upham 2009). Air travel emits 650 million tons of $\mathrm{CO}_{2}$ a year ${ }^{2}$ and is responsible for approximately $2 \%$ of annual anthropogenic $\mathrm{CO}_{2}$ emissions or $10 \%$ of total emissions from transport, with estimates suggesting that it could rise to $3 \%$ of global emissions by 2030 and to 5\% by $2050 .{ }^{3}$ Longer flights and more passengers have entailed a rapid growth of total passenger kilometers (pKm) traveled, from 28 billion pKm in 1950 to 5.4 trillion $\mathrm{pKm}$ in 2012. In 2012, aviation moved almost three billion people, a growth rate of almost $5 \%$ over the previous year and up from 960 million passengers in 1986 and 31 million in $1950 .{ }^{4}$ Improved aircraft and engine design and materials, as well as improved air control and airport operations, have decreased the unit 
rate of emissions, but alone these factors are not enough to curb the predicted future increase of emissions..$^{5}$

In other words, aviation is under normative pressure to address its growth of GHG emissions, but needs to do so in a global, comprehensive manner - given that it operates at extremely low margins (Doganis 2001: 2-4). Yet, the international organization that regulates the industry (ICAO) has historically failed to seriously tackle the environmental impacts its operators. The other international agreement that could have regulated at least GHG emissions (the Paris Agreement) failed to include aviation in its remit. Therefore, a combination of normative pressure and regulatory failure at the global level entails that national and regional governments have taken (and kept) the mantle of orchestrators. As a result, the industry is now focused on regulating and supporting the development of renewable jetfuels ('aviation biofuels' hereafter). ${ }^{6}$

Second, the emergence of aviation biofuels as the principal response to the normative pressures on the aviation industry makes it a critical case for exploring the role of networks in orchestration of TEG. The aviation biofuels industry is an emergent industry that springs out of production networks in the general biofuels industry and has strong ties and affinities with the biotech industry. These industries are largely based on network forms governance (Author Reference withdrawn; (Powell and Brantley, 1992; Powell, Koput, and Smith-Doerr, 1996) - 'coordination characterized by informal social systems rather than by bureaucratic structures within firms and formal contractual relationships between them' (Jones, Hesterly, and Borgatti 1997: 911; see also Piore \& Sabel, 1984; Powell, 1990; Ring \& Van de Ven, 1992; Snow, Miles, \& Coleman, 1992) but with a much more heavy involvement of governments in the coordination of complex products and services in what is an uncertain and competitive environment (Upham, Tomey and Boucher 2009). This industry structure makes it crucial to understand and analyze the overall network structure of actors within the industry - as well as the particular embedding of public actors - in order to understand overall governance dynamics. The network governance literature has firmly established the importance of network structure for intra- and inter-firm governance (Jones, Hesterly, and Borgatti 1997) but rarely theorizes the role of public actors in coordination and collaboration of industries.

To examine the development of orchestration in the aviation industry, we therefore followed a twostep methodological approach: (1) First, we applied a qualitative-interpretative approach to primary and secondary material, mainly drawn from semi-structured interviews with industry stakeholders and attendance of presentations at seven biofuel and bioenergy conferences we attended from September 2011 to April 2013. ${ }^{7}$ These conferences had either special panels or specific 
presentations on biofuels use in the aviation sector (civil or military). During these biofuel-focused conferences, one or the other author attended over 175 presentations on biofuels and established contacts that led to over 100 interviews (face-to-face and/or via email or phone). Out of these, 35 of the attended presentations (in addition to another 21 for which overhead slides have been made available to the authors) and 15 interviews dealt mainly with aviation biofuels - although many other interviews and presentations also touched upon this sector. Interviewees were offered full confidentiality. This first step was used to systemically identify the institutional features and trajectories of TEG in aviation biofuels.

(2) Second, we mapped the transnational network of industry actors and experts involved in aviation biofuel. Through a snowball sampling method, we identified the social ties between actors who are transnationally recognized for their aviation biofuel expertise. We applied Social Network Analysis (SNA) to map the presence of public sector actors in the network and to locate who they forge ties with.

The transnational network was located through a social network snowball e-survey. The survey was initially sent to 160 aviation biofuel experts who were identified from objective criteria, such as event attendance and formal group membership, including: fieldwork-based interviews with experts and presenters at selected biofuel conferences; desk research identifying presenters at key conferences (from published programs); and the distribution email lists of two sustainable aviation initiatives for which we obtained permission. The criterion of inclusion in the network was that an individual had to be nominated, by a survey respondent, as a 'key member' of his/her 'professional network' in the aviation biofuel sector. One individual enumerating another as a key industry or expert peer is thus our measure of a directed social tie. Our total list of survey respondents evolved dynamically through six survey waves. The experts who were nominated by peers in the 'first wave' of the survey, and who had not been included in the first list, received the same survey - thus creating a 'second wave'. We reiterated this process for a total of six waves, when no additional new names emerged, which led us to consider our network sample saturated. Among the total of 275 surveyed individuals, 56 completed the network part of the questionnaire (24 left partial responses with no network information about their network peers). 193 professionals were nominated as experts by at least one of our 56 respondents. The ties reported between the actors connect into one social network component composed of 411 directed ties.

The low response $(20 \%)$ rate is problematic in a network analytical context, since structural traits of the entire network can rely heavily on ties that are missing from our sample (Borgatti 2006; Mestres 
2008). Some network analytic measures and techniques are robust enough to reliably handle large shares of missing nodes or edges, but others are fragile when faced with data incompleteness and sampling bias (Costenbader and Valente 2003). We tackle the issue of missing data by estimating and simulating the structural parameters for the underlying tie formation process using an Exponential Random Graph Model (ERGM) (Robins et al. 2007), a class of network models that is well-designed to deal with missing data (Robins et al. 2004) and demonstrated to be superior to alternative imputation techniques for missing network data (Huisman 2010). The ERGM is a form of network regression where the observed network structure is treated as the dependent variable. The aim is to accurately replicate this network by estimating the propensity of particular relational microstructures - for example the likelihood of public sector actors having ties with industry actors. Network simulations are then used to test the significance of these propensities given the statistical uncertainties, including missing data (Desmarais and Cranmer 2011). We estimate homophily and mixing coefficients from our collected network data using the ERGM package in the statistical software environment R (Hunter et al. 2008). Homophily is a trait of many networks, describing the tendency of actors who carry similar characteristics to form ties and form social clusters (McPherson 2001). Mixing is the propensity of actors with certain attributes to form ties in a network.

In order to have sufficient observations to estimate the model, we coded the regional location of actors as 'US', 'Europe' or 'Other' and their institutional traits as 'Government' (Government and Military), 'Industry’ (Aircraft \& engine manufacturers, Airlines, Biofuel producers, Industry associations, Professional services, R\&D firms, Other services) or 'Other' (including Universities, Multi-stakeholder initiatives and NGOs). Both ERGMs successfully predict the probability of edges in the network at the $>.05$ significance level, even considering the statistical uncertainty that comes with the missing data. We also successfully modeled significant homophily and mixing patterns. We present these results in greater detail in the analysis section. Additionally, we examine the response bias in Appendix 1. Aircraft \& engine manufacturers stand out as the most heavily underrepresented group in our sample (8\%) but our ERGMs take this into account when modeling the propensity of tie formation between different groups in the network. We discuss the implications of both in the concluding section, where we also explain what kinds of implications they may have for our conclusions. 


\section{Orchestrating the Transnational Environmental Governance of Aviation}

As mentioned earlier, aviation is a major and growing contributor to GHG emissions. For a long period, environmental rhetoric in the aviation industry was not backed up by actual regulatory measures that would substantially reduce $\mathrm{CO}_{2}$ emissions, thus it is now perceived as a major polluter. Improved aircraft and engine design and materials, air control and airport operations have decreased the rate of emissions per aircraft/Km flown (Gossling and Upham 2009), but alone these factors are not enough to curb the predicted increase of emissions given the expected future growth in the industry. Also, while design changes doubled the efficiency of commercial aircraft since 1960, progress was slower from the late-1980s to the early-2000s due to lower fuel prices and a tripling in the average age of aircraft (Ibid.). Aviation not only emits substantial amount of $\mathrm{CO}_{2}$, it also has a range of other environmental and health impacts - noise pollution, land degradation, disturbance of wildlife and biodiversity, and emission of other air pollutants. ${ }^{8}$ This combination of factors provides a major challenge in orchestrating the TEG of aviation towards lower emissions and in addressing other negative environmental externalities. Yet, higher oil prices in recent years have provided stronger economic incentives to improve efficiency efforts, given that fuel costs account for about a third of airline operating costs on average (Gossling and Upham 2009), and thus made it easier to facilitate the development of alternative fuels.

In the short period of ten years, we have witnessed the emergence of an aviation biofuel industry, from the development of production pathways, to demonstration-scale operations, and more recently to a few commercial-scale production facilities. Many other operations failed, and the mainstreaming of aviation biofuels seems to have slowed down in more recent year. Yet, ASTM, a voluntary standards developer, has designed and approved specifications for various biofuels; over twenty major airlines have pledged to use biofuels with lower carbon impact than regular jetfuel; and more than ten commercial airlines have been using a blend including biofuels in selected scheduled flights. In the rest of this section, first we examine directive orchestration instruments, including international and national regulation, threat of (stricter) regulation, provision of subsidies and mandates, public procurement and provision of direct financial support and investment. Second, we highlight facilitative orchestration instruments, where public authorities: facilitate or have hands-off influence on, and cooperate with, industry associations in the aviation and advanced biofuel industries; participate or support multi-stakeholder initiatives on sustainable aviation and/or aviation biofuels; fund large research projects; and are active participants in special aviation panels in the biofuel conference circuit. 


\section{Directive instruments}

Several directive orchestration instruments in the TEG of aviation have been focused on regulating and supporting the development of biofuels. For the time being the price of biofuel remains higher than for regular jetfuel, although the gap was closing previous to the recent drop in international oil prices. The aviation industry runs on very small margins and individual airlines cannot afford to pay extra for biofuels unless all airlines do. This means that aviation biofuels not only need subsidies and/or a system of taxes on fossil fuels for carbon emissions, but also a global governance framework to set up a level playing field. It also needs investment incentives and the creation of a volume of demand that is not currently present at market prices.

At the inter-governmental level, and in relation to GHG emissions but not strictly related to biofuels for aviation, several directive tools have been applied. Domestic flights were included in $\mathrm{CO}_{2}$ emission calculations of the Kyoto Protocol, and remain so in the Paris Agreement of 2015. However, international flights were not included in Kyoto, and remain excluded from the Paris Agreement as well. ICAO is supposed to regulate the environmental impact of aviation at the international level, but has done little until very recently. It was only at its $38^{\text {th }}$ Assembly in September 2013, that it agreed to develop a global market-based measure (MBM) of emissions from international aviation, but asked its members to report back only by 2016 - with a proposal for a scheme capable of being implemented by 2020. In February 2016, ICAO agreed on a global standard for $\mathrm{CO} 2$ emissions for aircraft, to be applied only from 2020 onwards and only to new aircraft. And in October 2016, it finally agreed on an MBM scheme, the Carbon Offsetting and Reduction Scheme for International Aviation (CORSIA). ${ }^{9}$ The scheme will be voluntary from 2021 to 2026 and mandatory thereafter. Offsets are expected to apply to around $80 \%$ of emissions, but only above 2020 levels.

At the regional and national levels, notable has been the EU's active attempt in 2012 to extend its Emission Trading Scheme (ETS) to international flights arriving in the EU. However, it delayed its application to 2016 due to opposition from the US and China in particular. Now that CORSIA has been enacted, the EU may actually change its approach, although this is too early to assess. Of specific relevance to our discussion is that for the EU ETS, biofuels count for zero emissions. In addition to its ETS, the EU Commission has taken a number of directive orchestration initiatives that have a direct bearing on the development and use of biofuels in aviation. The Renewable Energy Directive (2009/28/EC) ${ }^{10}$ on the promotion of the use of energy from renewable sources, established mandatory targets to be achieved by 2020 for a $20 \%$ overall share of renewable energy 
in the EU and a 10\% share for renewable energy in the transport sector. This directive also applies to biofuels used in aviation (including international flights), when sold in a Member State. Therefore aviation biofuels qualify for incentives by the Member States if they comply with the established sustainability criteria. To avoid the controversies that have plagued 'first generation' biofuels produced from feedstock that could be used for food and feed, the industry is developing 'advanced' biofuels - based on improved and new transformation processes of cellulosic material and other waste, and/or on the development of algae feedstock.

In the US, government support and the existence of a military/commercial industrial base have been of special importance in supporting the development of aviation biofuels. The Environmental Protection Agency (EPA) sets annual quotas of biofuel to be blended into fossil fuels. Fuel operators are obligated to meet certain quotas and are required to submit a certain amount of Renewable Identification Numbers (RINs). This provides opportunities for developing an aviation biofuel market, as these fuel pathways are now eligible for crediting and generating RINs in accordance with US Renewable Fuel Standards (RFS) regulation.

Important investment has been provided by US Department of Defense, the US Department of Agriculture (USDA), the Department of Energy (DoE) and the Federal Aviation Authority (FAA). The US military has promoted the testing and certification of biofuels, has secured the allocation of $\$ 510$ million on co-financing production facilities (together with USDA and DoE), and has started purchasing aviation biofuels for use in its aircraft. The justifications for directive public orchestration are multifaceted: from 'creating opportunity for rural America', including the production of feedstock from a variety of sources and bioprocessing opportunities in small towns; ${ }^{11}$ to improving energy security by decreasing oil imports and increasing oil price stability; and securing the long-term reliability of fuel supply to the military, diversifying fuel sources and increasing operational flexibility.

Of particular interest to our discussion is the special role that the US Navy has played in this realm. In 2009, the Secretary of the Navy announced that it would be on course to reduce its consumption of energy, decrease its reliance on foreign sources of oil, and significantly increase its use of alternative energy - in view of improving its combat capability and increase energy security. One of the five energy goals of this strategy was to demonstrate (by 2012) and then deploy (by 2016) a 'Great Green Fleet' that would include ships and aircraft using alternative sources of energy. ${ }^{12}$ The Navy demonstration conducted during the 2012 Rim of the Pacific (RIMPAC) exercise, the world's largest international maritime exercise, was a key step in the direction of the Navy's goal to use a 
$50 \%$ biofuel blend in its ships and aircraft by 2016. Although biofuels are still more expensive than regular military jetfuel, the Navy counts on having cost-competitive aviation biofuel within 2-3 years. Therefore, when the Great Green Fleet program was threatened in the US Senate and House armed services committee in May 2012, Congress reversed that decision on the basis of a national security argument of increasing war-fighting capability. This was the result of a unique coalition of military-industrial, environmental and agricultural interests. ${ }^{13}$

\section{Facilitative instruments}

Given the complex constellation of the aviation biofuel industry, any successful orchestration strategy has to provide facilitative support to a variety of actors, interests and multi-stakeholder initiatives. In order to construct an effective framework for the TEG of aviation, the actions of this complex group of actors need to align with the goals of public policy. To this end, direct orchestration, although necessary, is not sufficient on its own. It needs to be complemented by facilitiative means. Yet, ICAO has used very few facilitative orchestration instruments. In relation to netogiations leading to the development of CORSIA, it carried out two Global Aviation Dialogues (GLADs) in 2015 and 2016 to facilitate information sharing and exchange of ideas. In relation to biofuels, we could only identify two initiatives: (1) in 2010, it passed a resolution (A3719) 'encouraging' Member States and industry to actively participate in further work on sustainable alternative fuels for aviation as part of the basket of measures to limit carbon emissions from international aviation; and (2) in June 2012, it created the Aviation and Sustainable Alternative Fuels Expert Group to develop recommendations to further facilitate the global development and deployment of sustainable alternative fuels for aviation.

While ICAO was taking tentative and modest steps, the most important industry association, the International Air Transport Association (IATA), in 2010 decided to commit to carbon neutral growth by 2020 and to reducing carbon emissions by $50 \%$ by 2050 . IATA has 240 airlines in over 115 countries as members, carrying $84 \%$ of the world's air traffic. ${ }^{14}$ IATA took this step to provide a vision and aspirational goals that could allow its members to keep growing while improving their environmental impact and maintaining their 'license to operate' from the political system and civil society, as many industry actors perceived that they could soon be taxed for $\mathrm{CO}_{2}$ emissions, or to be asked to purchase ET certificates. IATA signaled that they would seek these reductions mainly through the adoption of biofuels, first in small quantities but with the goal of eventually flying most aircrafts on $50-50 \%$ blends of regular jetfuel and biofuel. 
In absence of ICAO activity in this realm, and given the proactive IATA stance, it was the US and the EU that took initiative as orchestrators, engaging with: industry associations, such as IATA itself, but also with Airlines for America and the Advanced Biofuels Association; the biofuel conference circuit, in particular the annual Advanced Biofuels Leadership Conference (ABLC) in the US, and the World Bio Markets conference in the EU - both of which organize special sessions on aviation biofuels; and a series of multi-stakeholder initiatives (MSIs) on 'sustainable aviation'.

In the USA, the most prominent MSI has been the Commercial Aviation Alternative Fuels Initiative (CAAFI), but the Midwest Aviation Sustainable Biofuel Initiative (MASBI) and Sustainable Aviation Biofuels Northwest (SAFN) have also played important roles. In the EU, regional/national initiatives of this kind are present in Germany (Airreg), France (GiFAS/IFP Energy Nouvelle), the Netherlands (SkyNRG), Spain (Bioqueroseno) and the Nordic region (NISA) (see full list of MSIs on sustainable aviation in Appendix Table 1). ${ }^{15}$ These initiatives have benefited from political and sometimes material support by individual governments and the EU. Government agencies (sometimes through these very MSIs) have been key players in forging bilateral/multilateral alliances on aviation biofuels, and government support has included the funding of several research centers focused on biofuels for aviation, both in the US and in the EU. ${ }^{16}$

As we have seen above, in the US, various government departments and agencies played a decisive direct role in providing political and financial support for aviation biofuels. But they have also played a more indirect role - without resorting to pure intermediation. The Federal Aviation Authority (FAA), for example, was pivotal in forming and then consolidating CAAFI, the first multi-stakeholder initiative of its kind, established in 2006. At that time, FAA called on key relevant stakeholders to provide responses to three concerns on aviation fuels: supply security, affordability and price stability, and environmental impact. As a result, the Aerospace Industries Association, Airlines for America and FAA formally established CAAFI, bringing together key players from the private sector, government and (later on) civil society. These three organizations (together with the Airports Council International/North America) are the current sponsors of CAAFI, which now counts approximately 300 stakeholders. CAAFI's main aim is to exchange information and coordinate stakeholder efforts in alternative aviation fuels, and its main activities center on technical workshops, industry conference participation and other outreach activities, lobbying, and communication with the news media. ${ }^{17}$

In the EU, several policy documents have provided ideational support to the aviation biofuel industry. In 2011, the EC adopted the White Paper 'The Transport 2050 Roadmap to a Single 
European Transport Area', ${ }^{18}$ which included 40 specific initiatives aimed at reducing Europe's dependence on imported oil and cut carbon emissions in transport by $60 \%$ by 2050 . The report 'Flightpath 2050 Europe's Vision for Aviation', ${ }^{19}$ also published in 2011, presented a long-term vision for European aviation and called for further improving the energy efficiency of aircraft and operations and highlights the need to produce liquid biofuels. A roadmap developed to support the achievement of Flightpath's goals and challenges called for increasing the share of biofuel use in aviation, from $2 \%$ in 2020 to at least $40 \%$ by 2050 - as set out in the Transport White Paper.

Finally, the 2013 'European alternative fuels strategy ${ }^{20}$ provided political strategies and specific actions towards the decarbonizing of transport without impacting on economic growth. It addressed for the first time the potential of new aviation fuels and highlighted the need for financing instruments and market incentives to support the construction of biofuel production plants for aviation.

Taken together, the US and the EU orchestrated the emergence of an aviation biofuel industry as a key element of enacting the transnational environmental governance of aviation more generally. It was the combination of directive instruments (including threat of regulation) and facilitative instruments that characterized their strategy, together with an active network engineering approach (see next section). However, four facilitating factors also contributed to successful orchestration: (1) high issue visibility, as the industry is consumer-facing and has a reputation for being a high $\mathrm{CO} 2$ emitter; (2) the alignment of interest between regulators and the main industry association, IATA, in view of the latter's need to address these perceptions and an overall threat of further regulation; (3) a narrow scope of regulation, given the predominant focus on $\mathrm{CO} 2$ emissions, rather than other environmental impacts of the industry; and (4) a low level of regulatory fragmentation at the domestic level, given that commercial aviation is regulated by the respective aviation authorities (and the Commissioner for Transport at the EU level).

\section{Orchestrators in the Transnational Network of Aviation Biofuels}

In view of weak regulatory presence of the designated 'global governor' for aviation (ICAO), what is missing from the orchestration picture so far (and from the literature on orchestration more generally) is an assessment of the extent to which a social network around aviation biofuels has formed at the transnational level and, if so, what place public actors have within it. This analysis is important because it sheds light on the strategies used by orchestrators to achieve their goals, including the possible shaping of some of the key factors we highlighted above, for example in terms of actively aligning the interest of public authorities and industry. From our social network analysis, we offer three main findings that are relevant for orchestration. In the following section, 
we bring together these and the findings from the previous section to discuss orchestration as a whole.

1) A cohesive transnational network of aviation biofuels professionals has formed, in the absence of a 'global governor'. Given that we started our snowball from an objectively qualified sample of professionals, a very real possibility would have been to find several fragmented networks identified through snowballing from regional and institutional groups. The fact that our sampling strategy has identified a fully connected network of 193 professionals in a very young industry is itself a noteworthy indicator that a socially-cohesive network is emerging. This is an essential element for successful orchestration because it provides one, integrated conduit for building relations of learning, information-sharing and trust across jurisdictions as well as public and private agencies. This informal network may well help coordinate and integrate regulatory effort transnationally in what would otherwise be complete fragmented interventions across separate jurisdictions- making it more likely that the variety of instruments used in orchestration 'play the same tune'. Twenty-six different countries are represented in this integrated network, with EU countries and the US equally dominant (37\%), and 'other' countries accounting for the remaining $25 \%$ of professionals. This finding also justifies our focus on the US and the EU in the qualitative analysis of orchestration initiatives carried out in the previous section.

Figure 1 also shows that the aviation biofuel network is made up of a relatively large share of highlevel professionals from various sectors ( $38 \%$ executive leaders). The most important categories of professionals in the network are from airlines and government agencies (16\%), followed by biofuel producers (15\%), R\&D professionals (11\%), and universities (10\%). Collectively, $18 \%$ of the network is made up of public sector professionals (government and military), 50\% are industry professionals broadly conceived (involved in $\mathrm{R} \& \mathrm{D}$, biofuel production, airline operation and aircraft and engine manufacturing), 19\% are professionals involved in knowledge and service provision (universities, professional services and other services), and $13 \%$ in collective action (NGOs, MSIs, industry associations). This means that industry operators dominate membership in the network, but public sector professionals have a substantial (but still minority) volume of presence, both directly and indirectly through MSI membership. This configuration provides legitimation to the network (in the eyes of industry) and - combined with the cohesive nature of the network discussed above - an optimal 'spreading out' architecture for orchestration. 
Figure 1: Network representation by categories (region, rank and organizational type).
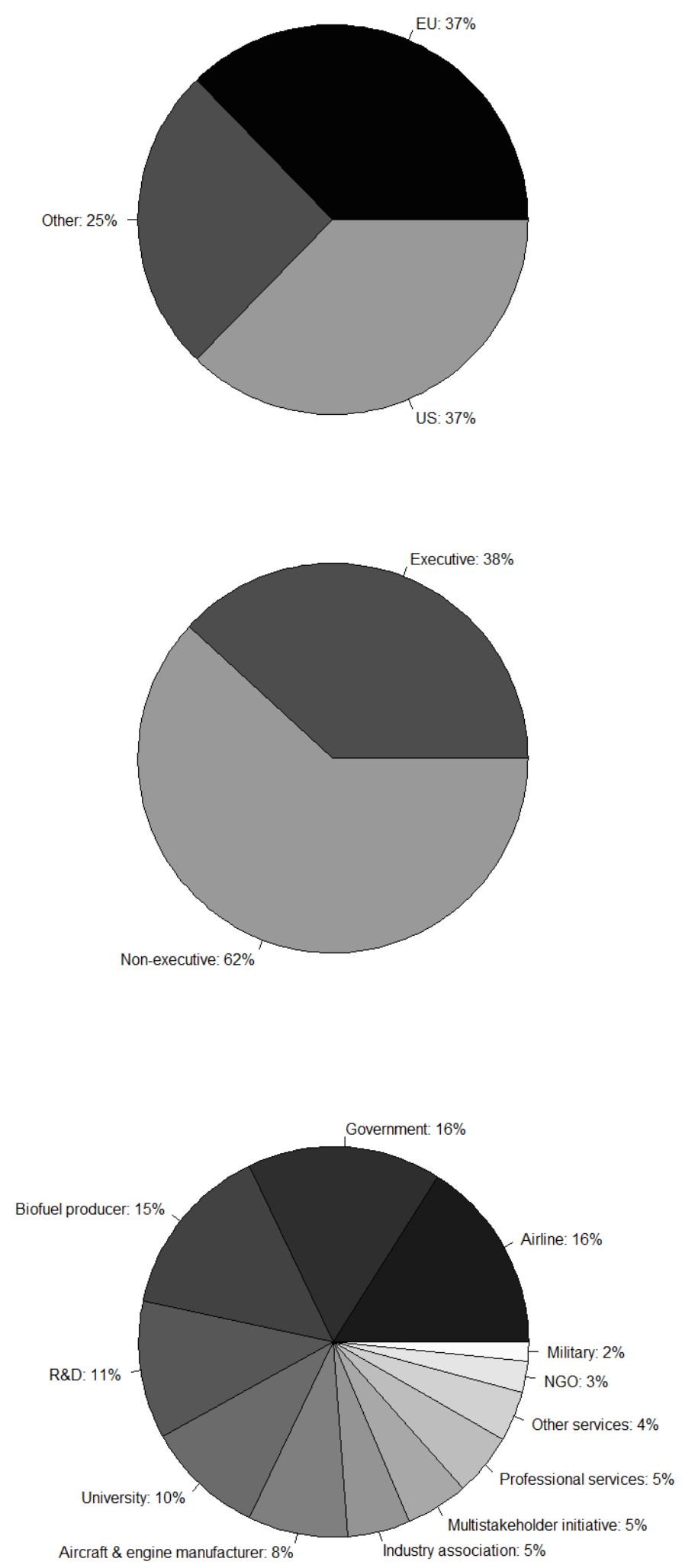
2) These propositions are strengthened by the analysis carried out in Figures 2 and 3, which shows that the network has a highly centralized structure - with a core of actors who were nominated as key professional peers by a regionally and institutionally diverse set of actors. Figure 2 is a graphical representation of the network using a spring algorithm, which places actors close to each other when they are connected. Figure 3 is plotted using a coreness layout, placing the actors on a continuum from core to periphery depending on their coreness score. ${ }^{21}$ Both graphs reveal a highly centralized network structure, another feature that can help orchestration.

The core-periphery structure demonstrated in the network graphs suggests the presence of a professional hierarchy in the network despite its extra-organizational character. Industry actors from the US and EU dominate the core, yet six public orchestrators are also present. The US orchestrators outnumber those from the EU and other countries significantly though. At the same time, different institutional and regional traits are represented within the core. This suggests that the core brings together a diverse set of professionals from different regions and institutions, and that public orchestrators are centrally embedded but do not completely dominate the core. This indicates that not only is there a connected network that can serve as an infrastructure for informationsharing, learning and trust-building, public orchestrators are central nodes within this network and play a core function within it. Again this enables public orchestrators access information about industry-level activities and to coordinate efforts across jurisdictions and public-private borders, while also placing them in a strategic position to disseminate information to industry about what might be coming ('regulatory threats'). 
Figure 2: Spring layout with professionals colored by regional and institutional traits.
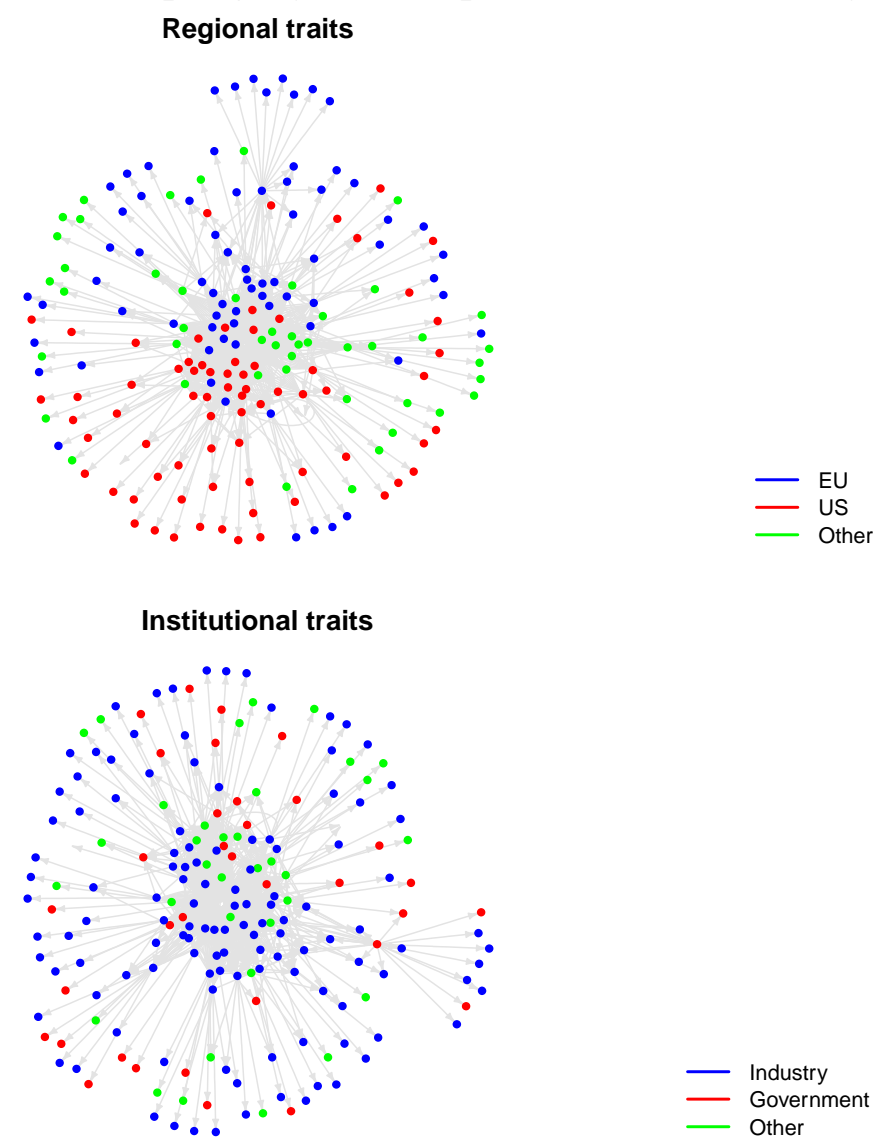

Note: Spring algorithm used in the top graphs to show network position based on connectivity. Coreness layout used in the bottom graphs to accentuate professional's position in the network hierarchy. 


\section{Figure 3.}

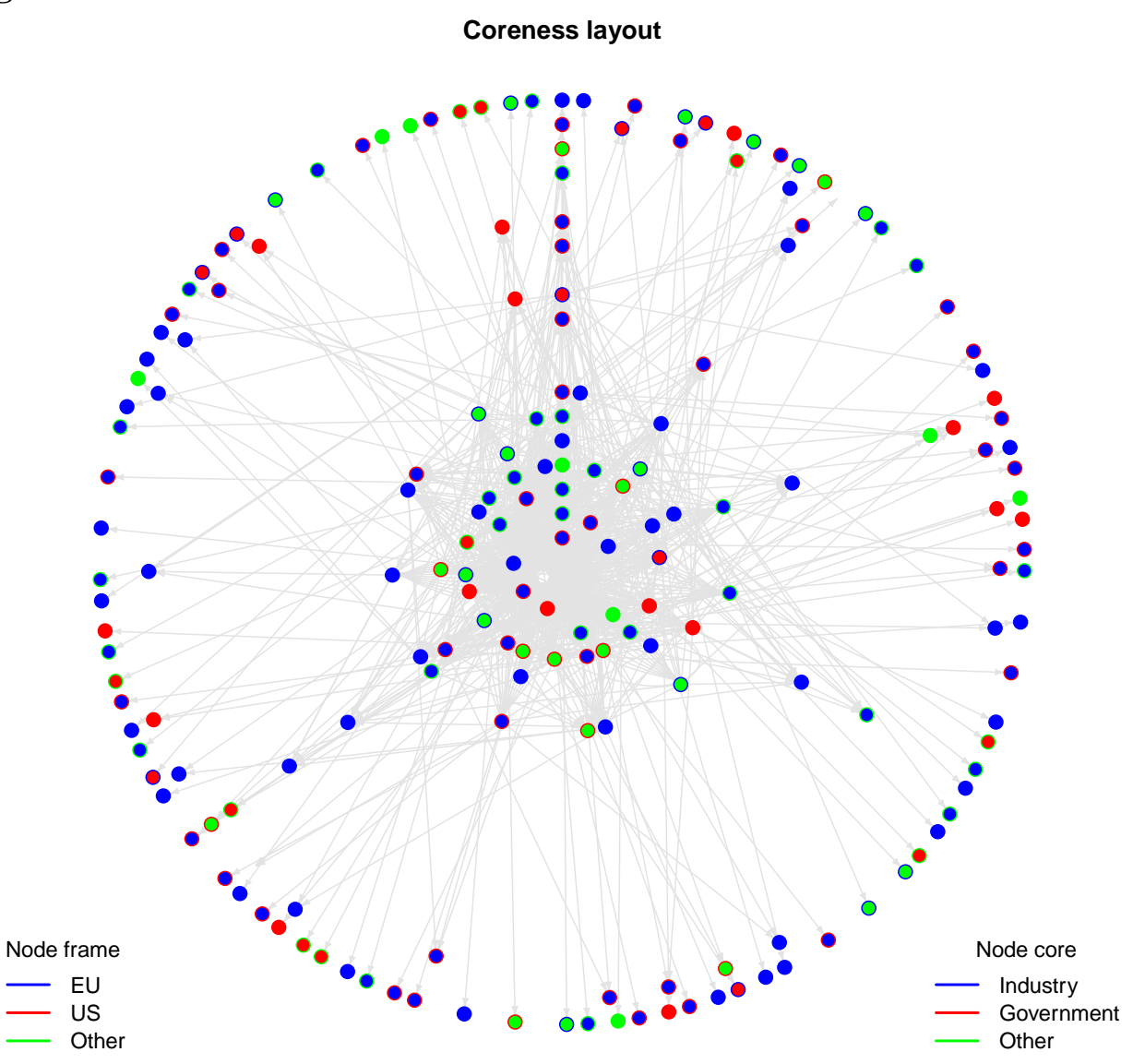

3) The network is characterized by regional homophily and by the importance of public agencies in mixing patterns. Our ERGM estimation (see Table 1) yields coefficient estimates as conditional logodds of directed ties being present. ${ }^{22}$ We tested general homophily on regional and institutional traits. We found regional homophily to be strong and significant, suggesting that ties tend to form between regionally similar alters, while this is not the case for institutional homophily ${ }^{23}$ (see the results for the nodematch variables in Table 1).

When we look more closely at specific mixing patterns for regional and institutional traits, we find that EU->US and Other->US ties are prevalent beyond random, suggesting that being connected to US professionals is important. Although institutional homophily is not significant, a closer look at mixing patterns reveals that homophilous Government->Government ties are prevalent as well as reciprocated heterophilous ties directed from Other->Government and Government->Other. This is evidence that, in general, public agencies show a high propensity to be nominated within the network. It should be noted that the propensity of Government ties directed at Industry professionals is non-negligible and almost significant at the .10-level. 
Table 1. Results of Exponential Random Graph Model (coefficients conditional log-odds)

\begin{tabular}{lllll} 
& Estimate & Std. Error & (Prob.) & P-value \\
\hline Edges & $-4.60^{* * *}$ & .329 & $(.010)$ & .000 \\
Nodematch regional traits & $1.98^{* * *}$ & .309 & $(.879)$ & .000 \\
Nodematch institutional traits & .109 & .179 & $(.527)$ & .544 \\
& & & & \\
Regional trait mixing: (base=USA->USA) & & & & \\
EU->US & $1.14^{* * *}$ & .321 & $(.758)$ & .000 \\
Other->US & $0.973^{* *}$ & .341 & $(.726)$ & .004 \\
US->EU & -.273 & .411 & $(.432)$ & .507 \\
EU->EU & .051 & .142 & $(.513)$ & .720 \\
Other->EU & .393 & .372 & $(.597)$ & .291 \\
US->Other & .130 & .411 & $(.532)$ & .751 \\
EU->Other & $\mathrm{NA}$ & $\mathrm{NA}$ & $\mathrm{NA}$ & $\mathrm{NA}$ \\
Other->Other & -.355 & .196 & $(.412)$ & .070 \\
& & & & \\
Institutional trait mixing: (base=Indust.->Indust.) & & & & \\
Government->Government & $.721^{* *}$ & .273 & $(.673)$ & .008 \\
Industry->Government & -.103 & .233 & $(.474)$ & .657 \\
Other->Government & $.569^{*}$ & .262 & $(.639)$ & .030 \\
Government->Industry & .372 & 0.231 & $(.592)$ & .107 \\
Other->Industry & -.097 & .215 & $(.476)$ & .651 \\
Government->Other & $.649 *$ & .325 & $(.657)$ & .046 \\
Industry->Other & $\mathrm{NA}$ & $\mathrm{NA}$ & $\mathrm{NA}$ & $\mathrm{NA}$ \\
Other->Other & 0.167 & .252 & $(.542)$ & .507 \\
\hline
\end{tabular}

Collectively, these three layers of social network analysis suggest that there is cohesive transnational network of aviation biofuel professionals, with clear regional and institutional traits. This network has a highly centralized structure whose core consists of a diverse set of actors including public officials - with firm grounding in industry. Finally, network members clearly see public officials as key members of the network. This suggests that public orchestration by national and regional authorities can occur through network formation and/or participation, even in the absence of an active international organization. Although SNA alone cannot show directly whether public officials are actively orchestrating the TEG of aviation, in combination with the interview and participant observation material presented in the previous section, it provides strong indications of orchestration in action. 


\section{Discussion}

Our case study of aviation shows that national and regional governments can and do take the mantle of orchestration when the relevant international organizations fail to do so. ICAO did not use delegation or intermediation instruments for transnational environmental governance, and resorted to cooperation only in very limited ways. Its failure in enacting these orchestration instruments is actually explained by several factors in Abbott et al.'s (2015) model, even though they refer more narrowly to intermediation: ICAO has high capabilities in the focal domain; there is no readily available intermediary; ICAO has low focality in the environmental field; it does not have an organizational structure that facilitates entrepreneurship; and there is strong oversight of member states in the focal domain (see Table 2). The characteristics of these five factors suggest that it would indeed be difficult for ICAO to orchestrate TEG in the aviation sector. At the same time, there is strong divergence of goals among member states within ICAO, which would have in theory facilitated orchestration.

A comparative analysis with the shipping industry (reference withdrawn) is useful at this point, since shipping is also a capital-intensive industry with mobile assets, and has managed to stay out of the Paris Agreement as well. The scorecard of Abbott et al.'s (2015) model as applied to the relevant international organization (the International Maritime Organization, IMO) is very similar, and indeed IMO has not been successful in orchestrating TEG either (see Table 2). All in all, Abbott et al.'s (2015) model seems to yield explanatory power in relation to whether international organizations are likely to act as orchestrators (but in the broader sense of the term, not only in relation to intermediation).

Table 2: Orchestration in aviation and shipping according to Abbott et al.'s (2015) model

\begin{tabular}{|l|c|c|c|}
\hline & Aviation & Shipping & $\begin{array}{c}\text { Model } \\
\text { prediction }\end{array}$ \\
\hline Regulatory capability & high & high & low \\
\hline Intermediary availability & low & low & high \\
\hline Focality & low & low & high \\
\hline Enterpreneurship & low & low & high \\
\hline Divergence of goals among members & high & high & high \\
\hline Oversight of states in their domain & high & high & low \\
\hline Orchestration by IO? & no & no & yes \\
\hline
\end{tabular}


Table 3: Orchestration in aviation and shipping according to (reference withdrawn) model

\begin{tabular}{|l|c|c|c|}
\hline & Aviation & Shipping & $\begin{array}{c}\text { Model } \\
\text { prediction }\end{array}$ \\
\hline Issue visibility & high & low & high \\
\hline Interest alignment & high & low & high \\
\hline Issue scope & low & high & low \\
\hline Regulatory fragmentation & low & high & low \\
\hline Orchestration? & yes & no & yes \\
\hline
\end{tabular}

However, Abbott et al's model is unable to account for why and how the US and the EU took up the mantle of orchestration successfully in the absence of orchestration by ICAO. In order to explain this, we now revert to the four explanatory factors we proposed earlier in the paper: issue visibility, interest alignment between government and industry, issue scope, and regulatory fragmentation. In Table 3, we summarize the results from the case study of aviation and compare them with the case study of shipping. Table 3, drawing from our analysis presented earlier in the article, suggests that successful orchestration in the aviation industry can be linked to: (1) high issue visibility, as aviation is clearly perceived by the public and consumers as a high GHG emitter; (2) alignment between US/EU regulators and the industry (through IATA and CAAFI) that something needs to be done to curb GHG emissions; (3) narrow issue scope, mostly focused on CO2 emissions; (4) low regulatory fragmentation within domestic/regional domains. On the contrary, (reference withdrawn) show that in the shipping industry these factors score exactly the opposite, and indeed orchestration of TEG so far has failed to emerge.

A final reflection is needed in relation to the actual orchestration trajectories observed in our case study of aviation. The two models presented so far clarify what factors facilitate orchestration, but not how orchestration actually unfolds. Our combined qualitative and social network analysis suggests that orchestration is more likely to be successful when a combination of directive and facilitative instruments are used, and when orchestrators are successful in forming and embedding themselves within the transnational networks that constitute the infrastructure of TEG. The latter is likely to have been particular crucial for coordinating the emergence of a transnational aviation biofuel industry, given that network forms of governance are already prevalent within such industries. 


\section{Conclusion}

In this article, we examined the emerging dynamics of public orchestration of transnational environmental governance (TEG) through the case study of aviation. While recent discussions in the literature have focused mostly on intermediation and delegation instruments (Abbott et al. 2015; Green 2014), we argue that there is analytical traction in studying orchestration as a combination of directive and facilitative tools, including network formation and/or consolidation.

Our analysis yields two sets of conclusions. One is that four factors facilitate public orchestration: high issue visibility; interest alignment between orchestrators and industry; narrow issue scope; low regulatory fragmentation. A second has to do with a two-pronged strategy: (1) public orchestrators have used both directive and facilitative measures to create feasible incentives, backed up by regulation or credible regulatory threat, that drove industry to innovate and change business models and operations in response to challenges of environmental change; and (2) public orchestrators have supported the creation of a global network of experts and other stakeholders, and actively embedded themselves into it - not only to stay up to speed with crucial recent industry information, but also to signal where policies are headed. Part of these networks evolved from the mainstream biofuel industry, but more specific one related to aviation had to be formed and connected to the principal public orchestrators of aviation biofuels as the principal response to the TEG challenge of the aviation industry- the national and regional governments of the US and the EU.

Industry events are especially important as instigators of such networks, and in time can lead to the solidification of social ties - a key condition for orchestrating the interplay of various governance instruments. Public orchestrators placed themselves at a social proximity with their regulatory objects in order to share information and learn; nudge and coordinate. They facilitated network formation and consolidation - the very infrastructure of collaboration and coordination - as well as occupied particular strategic spaces within such networks to maximize orchestration capacity given the material and institutional resources at hand. Furthermore, they placed themselves at the core of these networks and established links with a variety of stakeholders - without being perceived as dominating them.

However, it must also be underlined that the social proximity that arises from public orchestration also carries a risk of regulatory capture. Public officials working closely with their regulatory targets, in situations of rapid industry upscaling, may be more likely to buy into the business challenges of their network peers - and as a result may be more inclined to soften up on mandatory targets or the regulation of sustainability issues. In the financial industry, for example, a clear tendency has been for the career trajectories of public orchestrators to 'revolve' between public and 
private domains, a social dynamic that has been pointed out as a driver of deregulation. The possible feedback mechanisms that may occur between social network structures and public orchestration thus need further research.

In this article, we have focused on the social networks that are generated by public orchestration activities across public and private domains. What still needs to be better understood is how the structure of these networks influence the capacity of actors to orchestrate in the interest of the general public in the longer run. Finally, the four factors and two strategies that yielded successful orchestration in the aviation industry will have to be empirically tested in other industries and contexts in further research, especially in regulatory fields and industries that have more effective regulatory presence by an international organization.

\section{Endnotes}

\footnotetext{
${ }^{1} \mathrm{http}: / / w w w . e e a . e u r o p a . e u / d a t a-a n d-m a p s /$ figures/specific-co2-emissions-per-passenger-3 and http://www.eea.europa.eu/data-and-maps/figures/specific-co2-emissions-per-tonne-2

2 http://renewablejetfuels.org/what-we-do/the-basics

3 http://www.biofuelsdigest.com/bdigest/2014/04/21/biofuels-in-aviation-to-fly-or-not-to-fly and http://www.iata.org/whatwedo/environment/Documents/technology-roadmap-2013.pdf

${ }^{4} \mathrm{http}$ //www.biofuelsdigest.com/bdigest/2014/04/21/biofuels-in-aviation-to-fly-or-not-to-fly/

5 See Gossling and Upham (2009) and http://www.iata.org/whatwedo/environment/Documents/technology-roadmap2013.pdf

${ }^{6}$ Ibid.

7 [Author 2] attended the 'World Biofuels Markets -Brazil' congress and exhibition (Sao Paulo, 28-29 September 2011), the GreenPower Webinar 'Advanced biofuels: Steps to reaching the US EPA target of 20 bn gallons by 2012' (online, 6 October 2012), the 'Copenhagen Cleantech Cluster Annual Conference' (Copenhagen, 11 October 2011), the 'Bioenergy International Asia' expo \& conference (Kuala Lumpur, 7-8 December 2011), the 'ISCC Global Sustainability Conference' (Brussels, 8 February 2012), the 'World Biofuel Markets' congress and exhibition (Rotterdam, 13-15 March 2012), and the Advanced Biofuels Leadership Conference (Washington, DC, 15-17 April 2013). [Author 1] attended the $4^{\text {th }}$ International Conference on Biofuels Standards (Gaithersburg, Maryland, 13-15 November 2012).

${ }^{8}$ Source: http://www.worldwatch.org/global-air-transport-continues-expand-0

${ }^{9}$ Source: http://www.icao.int/environmental-protection/Pages/A39 CORSIA_FAQ1.aspx

${ }^{10}$ Directive 2009/28/EC of the European Parliament and of the Council of 23/04/2009 on the promotion of the use of energy from renewable sources and amending and subsequently repealing Directives 2001/77/EC and 2003/30/EC, Article 17 Sustainability criteria for biofuels and bioliquids, at pp.L140/36-L140/38.

11 Thomas Vilsack, US Secretary of Agriculture, conference presentation at ABLC, Washington DC 15/4/2013.

12 Julia Whitty, 'Full Green Ahead', Mother Jones, March/April 2013; Interview ABLC17, 15/4/2013; and http://www.navy.mil/submit/display.asp?story id=82044

13 'Full Green Ahead'.

14 www.iata.org

${ }^{15}$ Elsewhere, similar initiatives are present in Brazil (Abraba) and Australia (AiSAF).

${ }^{16} \mathrm{See}$ http://ec.europa.eu/energy/renewables/biofuels/doc/20130911 a performing biofuels supply chain.pdf

${ }^{17}$ Sources: www.caafi.org, CAAFI presentations at ABLC, Washington DC 15/4/2013, interviews ABLC21 and ABLC26, 15/4/2013. .

${ }^{18}$ COM (2011) 144 final of 28.03.2011, see: http://ec.europa.eu/transport/strategies/2011_white paper_en.htm

${ }^{19} \mathrm{http} / /$ ec.europa.eu/transport/modes/air/doc/flightpath2050.pdf

${ }^{20}$ COM (2013) 17, see http://cor.europa.eu/en/activities/stakeholders/Documents/com2013-17.pdf

${ }^{21} \mathrm{We}$ applied a K-core decomposition to test if the network consisted of a cohesive core, and it does (for details on this method, see Dorogovtsev et al. 2006). The k-core of graph is a maximal sub-graph in which each actor has at least indegree $\mathrm{k}$ (number of survey nominations). This method recursively prunes nodes with an indegree centrality $<k$ and
} 
assigns a coreness score $k$ to each actor in the network, depending on the point where it is excluded in the pruning process.

${ }^{22} \mathrm{We}$ also report the corresponding probability in parentheses to ease interpretation for non-experts.

${ }^{23}$ Note however that the category 'other' includes many different countries and that this increases the coefficient.

\section{References}

Abbott, K.W. and D. Snidal. 2009a. The Governance Triangle: Regulatory Standards Institutions and the Shadow of the State. In The Politics of Global Regulation, edited by W. Mattli and N. Woods, 44-88. Princeton: Princeton University Press.

Abbott, K.W. and D. Snidal. 2009b. Strengthening International Regulation Through Transnational New Governance: Overcoming the Orchestration Deficit. Vanderbilt Journal of Transnational Law (42): 501-78.

Abbott, K.W. and D. Snidal. 2010. International Regulation without International Government: Improving IO Performance through Orchestration. Review of International Organizations (5): $315-44$.

Abbott, K.W. and D. Snidal. 2013. Taking Responsive Regulation Transnational: Strategies for International Organizations. Regulation and Governance (7): 95-113.

Abbott, K.W., P. Genschel, D. Snidal, and B. Zangl. 2015. Orchestration: Global Governance through Intermediaries. In International Organizations as Orchestrators, edited by K.W. Abbott, K.W., P. Genschel, D. Snidal, and B. Zangl, 3-36. Cambridge: Cambridge University Press.

Albareda, L., 2008. Corporate responsibility, governance and accountability: from self-regulation to co-regulation. Corporate Governance 8 (4): 430-439.

Anderson, C.J., S. Wasserman and B. Crouch. 1999. A p* primer: Logit models for social networks. Social Networks 21 (1): 37-66.

Andonova, L.B. 2010. Public-Private Partnerships for the Earth: Politics and the Patterns of Hybrid Authority in the Multilateral System. Global Environmental Politics 10 (2): 25-53.

Andonova, L.B., M. Betsill, and H. Bulkeley. 2009. Transnational Climate Governance, Global Environmental Politics 9 (2): 52-73.

Andonova, L.B., and M.J. Hoffmann. 2012. From Rio to Rio and Beyond: Innovation in Global Environmental Governance. Journal of Environment and Development 21 (1): 57-61. 
Auld, G., 2014. Confronting Trade-Offs and Interactive Effects in the Choice of Policy Focus: Specialized versus Comprehensive Private Governance. Regulation and Governance 8 (1): $126-48$.

Avant, D. D., M. Finnemore, and S.K. Sell (Eds.) 2010. Who Governs the Globe? Cambridge: Cambridge University Press.

Cambridge University Press.Ayres I. and J. Braithwaite. 1992. Responsive Regulation: Transcending the Deregulation Debate. Oxford University Press: New York.

Bäckstrand, K. 2008. Accountability of Networked Climate Governance: The Rise of Transnational Climate Partnerships. Global Environmental Politics 8 (3): 74-102.

Bartley, T. 2007. Institutional Emergence in an Era of Globalization: The Rise of Transnational Private Regulation of Labor and Environmental Conditions. American Journal of Sociology 113 (2): 297-351.

Bartley, T. 2014. Transnational Governance and the Re-Centered State: Sustainability or Legality? Regulation and Governance (8): 93-109.

Bavelas, A. 1950. Communication Patterns in Task Oriented Groups. Journal of the Acoustical Society of America (22): 271-82.

Bernstein, S., and B. Cashore. 2007. Can Non-State Global Governance Be Legitimate? An Analytical Framework. Regulation and Governance (1): 347-71.

Biermann, F., P. Pattberg, H. van Asselt, and F. Zelli. 2009. The Fragmentation of Global Governance Architectures: A Framework for Analysis. Global Environmental Politics 9 (4): $14-40$.

Black, J. 2003. Enrolling actors in regulatory systems: Examples form UK financial services regulation. Public Law, Spring: 63-91.

Black, J., 2008. Constructing and contesting legitimacy and accountability in polycentric regulatory regimes. Regulation and Governance 2: 137-164.

Bonacich, P. 1987. Power and Centrality: A Family of Measures. American Journal of Sociology (92): 1170-82.

Borgatti, S.P., and D.S. Halgin. 2011. On Network Theory. Organization Science 22 (5): 1168-81.

Borgatti, S.P. 2002. NetDraw Software for Network Visualization. Lexington, KY: Analytic Technologies. 
Braithwaite J. and P. Drahos. 2000. Global Business Regulation. Cambridge University Press: Cambridge,

Bulkeley, H., L. Andonova, K. Backstrand, M. Betsill, D. Compagnon, R. Duffy, A. Kolk, M. Hoffman, D. Levy, P. Newell, T. Milledge, M. Paterson, P. Pattberg, and S. VanDeveer. 2012. Governing climate change transnationally: assessing the evidence from a database of sixty initiatives. Environment and Planning C: Government and Policy (30): 591-612.

Büthe, T., and W. Mattli. 2011. The New Global Rulers: The Privatization of Regulation in the World Economy. Princeton: Princeton University Press.

Cashore, B., G. Auld, and D. Newsom. 2004. Governing through Markets: Forest Certification and the Emergence of Non-State Authority. New Haven, CT: Yale University Press.

Cutler, A.C., V. Haufler and T. Porter. 1999. Private authority and international affairs. In A.C. Cutler, V. Haufler and T. Porter, eds. Private Authority and International Affairs. Albany: State University of New York Press, 3-30.

Desmarais, B. A., and S. J. Cranmer. 2012. Statistical Mechanics of Networks: Estimation and Uncertainty. Physica A: Statistical Mechanics and its Applications 391(4): 1865-1876.

Doganis, R. (2001) The Airline Business in the 21st Century. London: Routledge.

Dorogovtsev, S. N., A. V. Goltsev, and J. F. F. Mendes. 2006. K-core organization of complex networks. Physical review letters 96(4).

Dingwerth, K., and P. Pattberg. 2009. World Politics and Organizational Fields: The Case of Transnational Sustainability Governance. European Journal of International Relations, 15 (4): $707-44$.

Eberlein, B., Abbott, K. W., Black, J., Meidinger, E., \& Wood, S. 2014. Transnational business governance interactions: Conceptualization and framework for analysis. Regulation \& Governance, 8(1): 1-21.

Foley, P. 2013. National Government Responses to Marine Stewardship Council (MSC) Fisheries Certification: Insights from Atlantic Canada. New Political Economy 18 (2): 284-307.

Fransen, L., 2012. Multi-stakeholder governance and voluntary programme interactions: Legitimation politics in the institutional design of Corporate Social Responsibility. SocioEconomic Review, 10 (1): 163-192. 
Fransen, L. 2015. The politics of meta-governance in transnational private sustainability governance. Policy Sciences 48: 293-317.

Fransen, L., J. Schalk and G. Auld 2016. Work ties beget community? Assessing interactions among transnational private governance organizations in sustainable agriculture. Global Networks 16 (1): 45-67.

Freeman, L. C. 1979. Centrality in Social Networks Conceptual Clarification. Social Networks (1): 215-39.

Gale, F., and M. Haward. 2011. Global Commodity Governance: State Responses to Sustainable Forest and Fisheries Certification. Basingstoke and New York: Palgrave.

Gossling, S. and P. Upham (eds) 2009. Climate Change and Aviation. London: Earthscan.

Graham, E.R., and A. Thompson. 2015. Efficient Orchestration? The Global Environmental Facility in the Governance of Climate Adaptation. In International Organizations as Orchestrators, edited by K.W. Abbott, K.W., P. Genschel, D. Snidal, and B. Zangl, 114-38. Cambridge: Cambridge University Press.

Granovetter, M. 1985. "Economic Action and Social Structure: The problem of Embeddedness" American Journal of Sociology: 481-510.

Green, J.F. 2013. Order Out of Chaos: Public and Private Rules for Managing Carbon. Global Environmental Politics 13 (2): 1-25.

Green, J.F. 2014. Rethinking Private Authority: Agents and Entrepreneurs in Global Environmental Governance. Princeton: Princeton University Press.

Guldbrandsen, L.H. 2010. Transnational Environmental Governance: The Emergence and Effects of the Certification of Forests and Fisheries. Cheltenham: Edward Elgar.

Guldbrandsen, L.H. 2014. Dynamic Governance Interactions: Evolutionary Effects of State Responses to Non-State Certification Programs. Regulation and Governance 8 (1): 74-92.

Gunningham, N. 2009. Environment law, regulation and governance: Shifting architectures. Journal of Environmental Law 21 (2): 179-212.

Gunningham, N., and D. Sinclair 2002. Leaders and Laggards: Next-generation Environmental Regulation. Greenleaf.

Haas, P. 2004. Addressing the Global Governance Deficit. Global Environmental Politics 4 (4): 121. 
Hale, T., and C. Roger. 2014. Orchestration and Transnational Climate Governance, Review of International Organizations (9): 59-82.

Héritier, A., and S. Eckert 2008. New modes of governance in the shadow of hierarchy: selfregulation by industry in Europe. Journal of Public Policy, 28 (1): 113-138.

Hoffmann, M. 2011. Climate Governance at the Crossroads. Oxford: Oxford University Press.

Huisman, M. 2009. Imputation of Missing Network Data: Some Simple Procedures. Journal of Social Structure 10(1): 1-29.

Hunter, D. R., Handcock, M. S., Butts, C. T., Goodreau, S. M., \& Morris, M. 2008. Ergm: A Package to Fit, Simulate and Diagnose Exponential-Family Models for Networks. Journal of Statistical Software 24(3).

Jones, C., W. S. Hesterly, and S. P. Borgatti. 1997. “A general theory of network governance: Exchange conditions and social mechanisms" Academy of Management Review 22(4): 911945.

Keohane, R.O., and D.G. Victor. 2011. The Regime Complex of Climate Change. Perspectives on Politics (9): 7-21.

McPherson, M., Lynn S.-L., and J. M. Cook. 2001. Birds of a Feather: Homophily in Social Networks. Annual Review of Sociology 27: 415-444.

Meidinger, E. 2009 Private Import Safety Regulation and Transnational New Governance. In: Import Safety: Regulatory Governance in the Global Economy, edited by C. Coglianese, A.M. Finkel and D. Zaring. University of Pennsylvania Press: Philadelphia, pp. 233-256.

Mills, G. 2016. The interaction of private and public regulatory governance: The case of association-led voluntary aviation safety programs, Policy and Society 35: 43-55.

Overdevest, C. 2010. Comparing Forest Certification Schemes: The Case of Ratcheting Standards in the Forest Sector. Socio-Economic Review (8): 47-76.

Overdevest, C., and J. Zeitlin. 2014. Assembling an Experimentalist Regime: Transnational Governance Interactions in the Forest Sector. Regulation and Governance 8 (1): 22-48.

Pattberg, P.H. 2007. Private Institutions and Global Governance: The New Politics of Environmental Sustainability. Cheltenham: Edward Elgar.

Perez, O. 2011. Private Environmental Governance As Ensemble Regulation: A Critical Exploration of Sustainability Indexes and the New Ensemble Politics. Theoretical Inquiries in Law 12: 543-579. 
Piore, M. J., \& Sabel, C. F. 1984. The Second Industrial Divide. New York: Basic Books.

Ponte, S. and C. Daugbjerg. 2015. Biofuel Sustainability and the Formation of Transnational Hybrid Governance. Environmental Politics 24 (1): 96-114.

Powell, W. W., 1990. "Neither market nor hierarchy: Network forms of organization”. In B. Staw \& L. L. Cummings (Eds.), Research in Organizational Behavior, 295-336. Greenwich, CT: JAI Press.

Powell, W. W., and Brantley, P. 1992. "Competitive cooperation in biotechnology: Learning through networks?” In N. Nohria \& R. G. Eccles (Eds.), Networks and Organizations: Structure, Form, and Action, 366-394. Boston: Harvard Business School Press.

Powell, W. W., Koput, K., \& Smith-Doerr, L. 1996. Interorganizational Collaborations and the Locus of Innovation: Networks of Learning in Biotechnology. Administrative Science Quarterly 41: 116-145.

Ring, P. S., \& Van de Ven, A. H. 1992. "Structuring Cooperative Relationships between Organizations" Strategic Management Journal 13: 483-498.

Robins, G., Pattison, P., Kalish, Y., \& Lusher, D. 2007. An Introduction to Exponential Random Graph (p*) Models for Social Networks. Social Networks 29(2): 173-191.

Robins, G., P. Pattison, and J. Woolcock. Missing Data in Networks: Exponential Random Graph (p*) Models for Networks with Non-Respondents." Social Networks 26.3 (2004): 257-283.

Schleifer, P. 2013. Orchestrating Sustainability: The Case of European Union Biofuel Governance. Regulation and Governance 7 (4): 533-46.

Sinclair, D. 1997. Self-regulation versus command and control? Beyond false dichotomies. Law \& Policy 19 (4): 529-559.

Snow, C. C., Miles, R. E., \& Coleman, H. J., Jr. 1992. "Managing 21st Century Network Organizations" Organizational Dynamics 20(3): 5-20.

Upham, P., J. Tomei, and P. Boucher. 2009. "Biofuels, Aviation and Sustainability: Prospects and Limits." In Climate Change and Aviation: Issues, Challenges and Solutions, 309-328. London: Earthscan.

Verbruggen, P. 2013. Gorillas in the Closet? Public and Private Actors in the Enforcement of Transnational Private Regulation. Regulation and Governance 7 (4): 512-32.

Vogel, D. 2008. Private global business regulation. Annual Review of Political Science, 11: 261282. 
Zelli, F., and H van Asselt. 2013. The Institutional Fragmentation of Global Environmental

Govenance: Causes, Consequences, and Responses. Global Environmental Politics 13 (3): 113. 